\title{
Interventions at Hospital Discharge to Guide Caregivers in Medication Management for People Living with Dementia: a Systematic Review
}

\author{
Mouna J. Sawan, B.Pharm, Hons, $P h D^{7}$ (1), \\ Damian Wennekers, Bachelor of science in Pharmacy (Bsc.) ${ }^{2}$, \\ Marissa Sakiris, B.Pharm, Hons' ${ }^{7}$, and Danijela Gnjidic, BSC (Hons) PhD MPH \\ 'School of Pharmacy School, Faculty of Medicine and Health, The University of Sydney, Camperdown, NSW, Australia; ${ }^{2}$ School of Pharmacy, \\ Faculty of Science, University of Utrecht, Utrecht, The Netherlands; ${ }^{3}$ Charles Perkins Centre, The University of Sydney, Camperdown, NSW, Australia.
}

BACKGROUND: Hospital discharge has a significant impact on the continuity of care for people living with dementia. Clear guidance on medication management should be provided to caregivers of people living with dementia to ensure appropriate use of medications post-discharge.

AIM: Identify and appraise the impact of interventions at hospital discharge to guide caregivers in the medication management for people living with dementia.

METHOD: A systematic search of original studies was performed in Medline, Embase, PsycINFO, and CINAHL. Articles published in English that reported on interventions to guide caregivers in medication management for people living with dementia were included. Two authors independently reviewed titles and abstract. Full-text articles were assessed for eligibility and quality assessment was conducted by two authors.

RESULTS: A total of five studies were included with a range of interventions that were typically delivered postdischarge by a multidisciplinary team and most targeted administration of medications by caregivers. Overall, three types of discharge interventions were identified including a pre-discharge caregiver educational intervention, a postdischarge multidisciplinary team intervention, and discharge summary documentation intervention at transitions of care. Of these, a pre-discharge caregiver education led to shorter hospital stay ( 25 days vs. 31 days, $p=0.005$ ). A post-discharge intervention that included follow-up visits resulted in lower use of high-risk medications (19\% vs. $40 \%$ ), and reduction in 30-day re-hospitalization rates (11\% vs. 20\%). In contrast, in another post-discharge intervention study, no difference in one-month re-hospitalization rates $(8.4 \%$ vs. $8.0 \%, p=0.82)$ was demonstrated. In another study, a post-discharge hospital educational program provided to caregivers led to significantly reduced caregiver burden $(31.7 \pm 17.6$ (SD) pre-intervention to 27.7 \pm 16.9 (SD) post-intervention $(p=0.037)$ ).

DISCUSSION: Current findings suggest there is a need for well-designed interventions to guide caregivers in all aspects of medication management for people living with dementia, and should include support for caregivers in care coordination.

Received June 30, 2020

Accepted December 10, 2020

Published online February 3, 2021
KEY WORDS: dementia; caregivers; hospitalization; discharge planning; transitions of care; medication safety.

J Gen Intern Med 36(5):1371-9

DOI: $10.1007 /$ s11606-020-06442-5

(C) Society of General Internal Medicine 2021

\section{INTRODUCTION}

Dementia is one of the major causes of disability among older adults worldwide. ${ }^{1}$ People living with dementia place a high burden on acute care services due to frequent and longer hospitalizations compared to older adults without dementia. ${ }^{2,3}$ Hospital admissions caused by adverse drug events are three times higher in people living with dementia, compared with people without dementia, respectively, $14.0 \%$ and $4.2 \% .^{2-4}$ People living with dementia often have multi-morbidities and are frequently prescribed multiple medications, leading to an increased risk of preventable medication-related hospital admissions. $^{3-5}$ The informal caregiver plays an important role in managing medications for a person with dementia, as they may conduct up to 10 medication management activities per day. ${ }^{6,7}$ The complexities of managing medications increase with the progression of their care recipient's dementia which also contributes to caregiver burden. ${ }^{8}$

Caregivers' role in medication management includes not only maintaining supply and assisting with the administration of medications but also communicating with health care providers and the person they care for. ${ }^{9,10}$ Medication management also includes staying informed about the prescribed medication, monitoring for medication-related harm, and making decisions about medications when the person living with dementia is no longer able to do this. ${ }^{11}$ It is estimated that $54 \%$ of caregivers are actively involved in medication management of a person living with dementia, which is almost two times greater compared with caregivers of people with other diseases. $^{12,13}$ In later stages of dementia, over $90 \%$ of caregivers are actively involved in medication management. ${ }^{12,13}$ Due to unique responsibilities of managing medications for a person living with dementia, it is important to provide caregivers with tailored medication management guidance at discharge. 
In 2016, the World Health Organization recognized the transition of care to be high-risk and endorsed a set of actions to ensure coordination and continuity of transitions of care between health care settings. One of these actions is to support and educate the person living with dementia and their caregiver to improve medication safety. The discharge process includes verifying patients' medication lists, ensuring patients understand what medications they are taking, how long and why, and communicating the discharge summary to the patient's primary care physician. ${ }^{14}$ Caregivers of people with dementia have described that the medication guidance provided at discharge is limited due to a lack of information and support. ${ }^{9}$ Therefore, the aim of our systematic review was to identify and appraise the impact of interventions at hospital discharge to guide caregivers in medication management for people living with dementia.

\section{METHODS}

This systematic review was conducted in accordance with the Preferred Reporting Items for Systematic Reviews and MetaAnalyses (PRISMA). ${ }^{15}$ The systematic review protocol was not registered.

\section{Eligibility Criteria}

Original quantitative and mixed methods studies which evaluated discharge interventions to guide caregivers in medication management for people living with dementia were included. Studies were included if they tested an intervention that provided medication guidance to caregivers at pre-discharge, post-discharge, or transitions of care interventions (bridging interventions). Intervention studies that aimed to improve the management of dementia were also included, if it was related to medication management guidance provided to caregivers of people living with dementia. Studies published in any year were included. Studies were excluded if they (i) were unrelated to discharge interventions to guide caregivers in medication management for people living with dementia; (ii) involved caregivers of people without a dementia diagnosis; (iii) were written in languages other than English; or (iv) were case reports, expert opinion, reviews, or abstracts.

\section{Identification of Studies}

Systematic searches for relevant articles were conducted in four electronic databases, namely Medline, Embase, PsychINFO, and CINAHL from inception until 17 January 2020. Medical Subject Headings and key words were chosen in collaboration with a reference librarian which were searched in a Boolean search strategy. The search strategy included four concepts: caregivers, dementia, hospitalization, and medication management (see Supplementary Appendix table S1). This key word search was employed across all four databases and when available, was supplemented with relevant thesaurus (MeSH or Emtree) terms.
Following the removal of duplicates, articles were initially screened according to title and abstract independently by two reviewers (MAS and DW). Subsequently, the remaining full-text articles were assessed for eligibility independently by two reviewers (MJS and DW). Articles searched through the reference list of full-text articles by two reviewers (MJS and DW) were also included. Where there was disagreement between reviewers, discrepancies were resolved by a third reviewer (DG).

\section{Data Extraction and Analysis}

Data extraction was performed independently by two investigators (MJS, DW) using a standardized data extraction tool. Data extracted included author, year, country, study design, participant characteristics, number of medications, type of discharge intervention, aspect of medication management targeted, component and description of the discharge intervention, provider, and key findings. We also extracted information on any medication, caregiver, and clinical study outcome reported, such as quality indicators for prescribing, caregiver burden, re-hospitalization, and length of hospital stay. For the purpose of this review, medication management was defined as steps underpinning medication management, and included the initiation, supply, administration, review, monitoring, and cessation of medications. ${ }^{16}$ The discharge intervention was defined according to the taxonomy developed by Hansen et al. ${ }^{17}$ to categorize discharge interventions. The categories are separated into three domains: pre-discharge, post-discharge, and transitions of care (bridging interventions). The categories are not mutually exclusive and were used as a guide for the systematic review.

Given the heterogeneity of the study designs and interventions in the included studies, a meta-analysis was not be feasible.

\section{Quality Assessment}

An assessment of quality was completed for all articles using the Mixed Methods Appraisal Tool (MMAT) as it can be applied to quantitative, qualitative, and mixed methods studies. ${ }^{18,19}$ Quality assessment was conducted by DW and MJS. Disagreements were resolved by a third reviewer (DG). Studies were not excluded based on quality.

\section{RESULTS}

\section{Study Selection}

A total of 12,632 articles were identified, with an additional article identified from screening reference lists. After removal of duplicates, 7397 articles were screened for eligibility based on title and abstracts (Fig. 1). The process resulted in 205 potentially relevant articles that were screened for full text. The aspect of medication management was not specified in two studies; however, these studies were included in the systematic review as caregivers were advised on medications 


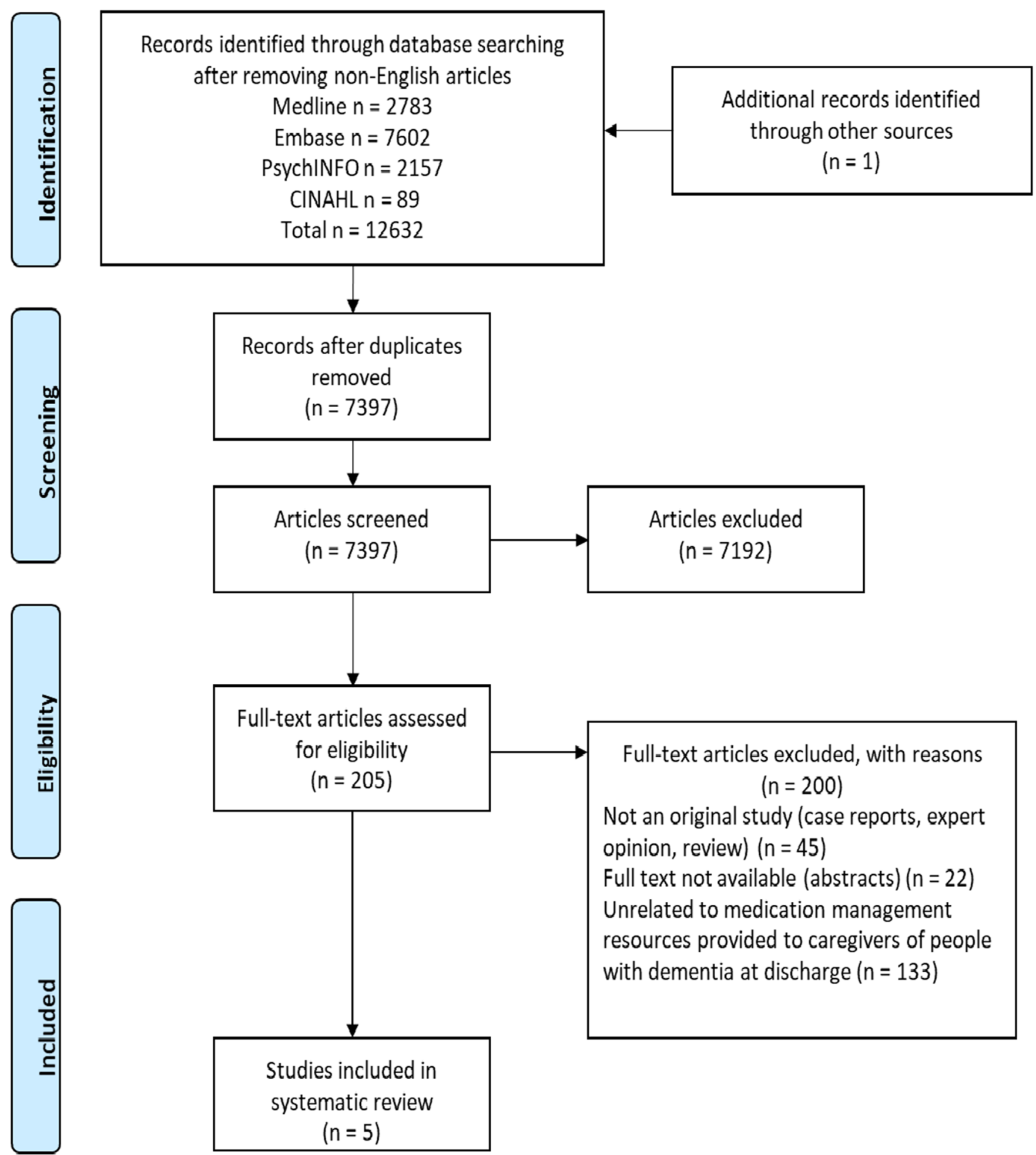

Figure 1 Preferred Reporting Items for Systematic Reviews and Meta-Analyses (PRIMSA) flowchart depicting study exclusion and inclusion criteria.

during admission..$^{20,21}$ A total of five articles met the inclusion criteria and were included in the systematic review.

\section{Study Characteristics}

The five included studies were from four countries: one in Australia, ${ }^{22}$ two in Japan, ${ }^{20,23}$ one in the USA, ${ }^{24}$ and one in
France. ${ }^{21}$ Of the included studies, three were non-randomized controlled trials (RCT), ${ }^{20,23,24}$ one was a quasi-experimental before and after comparison study, ${ }^{21}$ and one used mixed methods (cross-sectional study and questionnaire administration). ${ }^{22}$ Most studies investigated interventions delivered postdischarge that were typically delivered by a multidisciplinary 
Table 1 Characteristics of Included Studies $(n=5)$

\begin{tabular}{|c|c|c|c|c|c|}
\hline $\begin{array}{l}\text { Authors } \\
\text { (year), } \\
\text { country }\end{array}$ & $\begin{array}{l}\text { 1. Study design } \\
\text { 2. Participants } \\
(\mathrm{I}= \\
\text { intervention; } \\
\mathrm{C}=\text { control })^{\dagger} \\
\text { 3. Age, mean } \\
\text { (SD) }\end{array}$ & $\begin{array}{l}\text { 1. Type of discharge } \\
\text { intervention } \\
\text { 2. Health professionals } \\
\text { involved } \\
\text { 3. Component and } \\
\text { description of discharge } \\
\text { intervention }\end{array}$ & $\begin{array}{l}\text { Aspect of } \\
\text { medication } \\
\text { management }\end{array}$ & Outcomes measured* & Key findings \\
\hline $\begin{array}{l}\text { Boustani } \\
\text { et al. } \\
(2011) \text {, } \\
\text { USA }^{24}\end{array}$ & $\begin{array}{l}\text { 1. Non- } \\
\text { randomized con- } \\
\text { trolled trial } \\
\text { 2. I: } 208 \\
\text { C: } 1008 \\
\text { 3. I: } 73.8(9.5) \\
\text { C: NR }\end{array}$ & $\begin{array}{l}\text { 1. Post-discharge } \\
\text { 2. Geriatric team } \\
\text { 3. Discharge planning, } \\
\text { follow-up (face-to-face) } \\
\text { visits, telephone and/or } \\
\text { email, comprehensive as- } \\
\text { sessment of caregiver's } \\
\text { stress and the patient's be- } \\
\text { havioral and psychological } \\
\text { condition; caregiver } \\
\text { counselling; medication re- } \\
\text { view and simplification of } \\
\text { the patient's medical regi- } \\
\text { men }\end{array}$ & $\begin{array}{l}\text { Administration } \\
\text { (adherence), } \\
\text { medication } \\
\text { review }\end{array}$ & $\begin{array}{l}\text { Hospitalizations. High- } \\
\text { risk medication use. Di- } \\
\text { abetics: HgbA1c; LDL < } \\
\text { 130; } 30 \text {-day re-hospitali- } \\
\text { zation rates }\end{array}$ & $\begin{array}{l}\text { Compared to the control group, } \\
\text { intervention group had lower use } \\
\text { of high-risk medications (19\% } \\
\text { vs. } 40 \%) \text { and reduction in the } \\
\text { proportion of patients hospital- } \\
\text { ized within } 30 \text { days of discharge } \\
(11 \% \text { vs. } 20 \%) \text {. Adherence not } \\
\text { reported; however, the authors } \\
\text { reported higher rates of disease } \\
\text { state control for hyperlipidemia } \\
(45 \% \text { vs. } 23 \%) \text { and diabetes } \\
(78 \% \text { vs. } 51 \%) \text { compared to a } \\
\text { control group }\end{array}$ \\
\hline
\end{tabular}

Kable et al. 1. Mixed

(2019),

Australia $^{22}$ methods study (cross-sectional study and surveys) 2. 73 patients 3. NR
1. Bridging intervention

2. NR

3. Discharge summary documentation provided to primary care physician and patients living with dementia and their caregivers
Medication administration, medication monitoring
A compliance score of the discharge information provided to patients and caregivers was calculated as the proportion of discharge information that complied with the requirements of the 11 expected criteria outlined in state-based guidelines. Re-hospitalization at 3 months
Kazui et al. (2004),
1. Nonrandomized controlled trial 2. I: 23

C: 20

3. I: $72.7(9.5)$

C: 77.6 (6)

$\begin{array}{ll}\begin{array}{l}\text { Terayama } \\ \text { et al. }\end{array} & \begin{array}{l}\text { 1. Non- } \\ \text { randomized con- } \\ (2018),\end{array} \\ \text { Japan }^{23} & \text { trolled trial } \\ & \text { 2. I: } 47 \\ & \text { C: } 36 \\ & \text { 3. I: } 65.3(14.5) \\ & \text { C: } 62.7(11.6)\end{array}$

1. Pre-discharge

2. Geriatric team

3. Caregiver education and discharge planning. The physician consulted with the caregiver and patient to explain treatment plan, patient's disease and symptoms, and appropriate treatment; the nurse advised the caregiver on strategies to manage BPSD; social worker explained care systems

1. Post-discharge

2. Geriatric team

3. Hospital caregiver education; 2 consecutive 1.5-h lectures per month explaining symptoms and progression of dementia, medication adherence, and

Missing items on the discharge summary documentation for the community physician included provision of medication dosedecision aids $(53 \%)$, provision of contact information for patient support groups $(6 \%)$, and advance care planning $(9 \%)$. Over $80 \%$ included documentation about medication and significant medication changes. Missing items on the discharge summary documentation for the patient/ caregiver included: 7-week supply of medications at discharge (67\%), requests for medication dose-decision aids to be prepared by the community pharmacist $(49 \%)$, signs and symptoms that require monitoring $(56 \%)$, recommended home medication review by pharmacist $(1 \%)$.

Almost $90 \%$ of discharge summary documentation included instructions for routine medications. There was no evidence that re-hospitalization at 3 months decreased as the compliance score increased (OR $0.99, p=0.33$ )

Over $80 \%$ of the caregivers in the intervention group were satisfied with the medical care provided. Most caregivers $(71 \%)$ in the intervention group reported advice provided by the medical staff was easily understood. However, $22 \%$ of nurses and $39 \%$ of physicians reported that intervention increased amount of work. Compared to the control group, length of hospital stay was significantly shorter in the intervention group ( 25 days vs. 31 days, $p=0.005$ ) Caregiver burden significantly

Medication Caregiver burden

administration measured using the Zarit (adherence)
Caregiver Burden

Interview (ZBI).

Depression symptoms measured using Center for Epidemiologic decreased in the intervention group; mean scores on the ZBI decreased from $31.7 \pm 17.6(\mathrm{SD})$ pre-intervention to $27.7 \pm 16.9$ (SD) post-intervention ( $p=$ $0.037)$. In the control group, mean score on the ZBI 
Table 1. (continued)

\begin{tabular}{|c|c|c|c|c|c|}
\hline $\begin{array}{l}\text { Authors } \\
\text { (year), } \\
\text { country }\end{array}$ & $\begin{array}{l}\text { 1. Study design } \\
\text { 2. Participants } \\
\text { (I = } \\
\text { intervention; } \\
\mathrm{C}=\text { control) } \\
\text { 3. Age, mean } \\
\text { (SD) }\end{array}$ & $\begin{array}{l}\text { 1. Type of discharge } \\
\text { intervention } \\
\text { 2. Health professionals } \\
\text { involved } \\
\text { 3. Component and } \\
\text { description of discharge } \\
\text { intervention }\end{array}$ & $\begin{array}{l}\text { Aspect of } \\
\text { medication } \\
\text { management }\end{array}$ & Outcomes measured* & Key findings \\
\hline $\begin{array}{l}\text { Villars et al. } \\
(2013) \\
\text { France }^{21}\end{array}$ & $\begin{array}{l}\text { 1. Quasi- } \\
\text { experimental be- } \\
\text { fore and after } \\
\text { comparison } \\
\text { 2. } 390 \text { patients } \\
\text { 3. } 81.79( \pm 7.37)\end{array}$ & $\begin{array}{l}\text { 1. Post-discharge } \\
\text { 2. Geriatric team } \\
\text { 3. Caregiver support via } \\
\text { discharge planning, timely } \\
\text { follow-up, home visit, } \\
\text { telephone call, caregiver } \\
\text { hotline; discharge plan } \\
\text { implemented in the } \\
\text { first week after discharge } \\
\text { and at } 1,3 \text { and } 6 \text { months; } \\
\text { telephone contact included } \\
\text { (1) tailored advice on } \\
\text { nonpharmacological and } \\
\text { pharmacological manage- } \\
\text { ment; (2) tailored advice on } \\
\text { home supports. Medical } \\
\text { consultation with consultant } \\
\text { at } 1 \text { month after discharge } \\
\text { and home visits }\end{array}$ & NR & $\begin{array}{l}\text { Studies Depression Scale } \\
\text { (CES-D). } \\
\text { EuroQoL-5 Dimensions } \\
\text { (EQ5D) was used to } \\
\text { measure QoL of the } \\
\text { caregiver }\end{array}$ & $\begin{array}{l}\text { significantly increased from } 24.9 \\
\pm 13 \text { to } 35.6 \pm 16.1(p=0.003) \text {. } \\
\text { In the intervention group, de- } \\
\text { pressive symptoms significantly } \\
\text { decreased; mean scores on the } \\
\text { CES-D decreased from } 14.5 \pm \\
9.2(\mathrm{SD}) \text { to } 12.1 \pm 7.5(\mathrm{SD})(p= \\
0.039) \text {. The control group result- } \\
\text { ed in significant increase in } \\
\text { symptoms of depression, } 12.4 \pm \\
\text { SD } 7.3 \text { pre-intervention to } 16.0 \pm \\
\text { SD } 10 \text { post-intervention, } p= \\
0.004 \text {. } \\
\text { No difference in QoL of } \\
\text { caregivers and patients was } \\
\text { reported } \\
\text { No difference in } 1 \text {-month emer- } \\
\text { gency room re-hospitalization } \\
\text { rates ( } 8.4 \% \text { vs. } 8.0 \%, p=0.82) \\
\text { when compared with re- } \\
\text { hospitalization rates in the year } \\
\text { prior to the intervention }\end{array}$ \\
\hline
\end{tabular}

RCT, randomized controlled trial; NR, not reported; NA, not applicable; BPSD, behavioral and psychological symptoms of dementia; ZBI, Zarit Caregiver Burden Interview; QoL, quality of life; *All included studies did not report on the number of medications; ${ }^{*}$ in all included studies, the control group was usual care

team and targeted administration of medications by caregivers. Characteristics and summary of the key findings of the included studies are summarized in Table 1.

Four studies tested the impact of post-discharge interventions on patient or caregiver outcomes. ${ }^{20,21,23,24}$ The intervention components varied; one study tested only caregiver education $^{23}$ while the remaining studies tested two or more components including caregiver education, ${ }^{20}$ discharge planning, ${ }^{20,21,24}$ follow-up visits, ${ }^{21,24}$ caregiver hotline, ${ }^{21}$ consultation with the geriatric team, ${ }^{20,21,24}$ counselling on caregiving skills, ${ }^{24}$ and medication review. ${ }^{24}$ One study used mixed methods to evaluate the content of a transitions of care intervention (caregiver instructions/information via discharge documentation). ${ }^{22}$

Pre-discharge Interventions. Kazui et al. ${ }^{20}$ tested a predischarge intervention which included two components: caregiver education and discharge planning. The intervention group targeted patients with dementia and their caregivers. A multidisciplinary intervention was delivered to caregivers during admission, where the nurse engaged with the patient to discuss strategies for management of behavioral and psychological symptoms of dementia (BPSD). Also, a meeting was held with the caregiver and physician to explain the treatment plan, patient's disease, and appropriate treatment. ${ }^{20}$ Caregivers were surveyed, and $71 \%$ reported that they understood the advice provided during hospitalization. The duration of hospital stay was shorter in the intervention group (25 days vs. 31 days, $p=0.005$ ) compared to the control though, $22 \%$ of nurses and $39 \%$ of physicians reported that the intervention increased the amount of work.

Post-discharge Interventions. Three studies evaluated postdischarge interventions which had a number of components including caregiver education, caregiver support, follow-up (face-to-face) visits, home visits, telephone call/email, caregiver hot-line, and medication review..$^{21,23,24}$ Only two studies tested a post-discharge intervention that had more than one component. ${ }^{21,24}$ Boustani et al. $^{24}$ non-randomly assigned 208 
patients living with dementia and their caregivers to a postdischarge program which involved follow-up (face-to-face) visits, telephone, and/or email and medication review. The goal of the intervention was to provide supportive management strategies based on assessment of caregiver stress and the patient's behavioral and psychological condition. The intervention was delivered by a geriatric team and included medication review for appropriateness and simplification of the patient's medical regimen. The intervention resulted in lower use of high-risk medications (19\% vs. $40 \%$ ) and reduction in 30-day re-hospitalization rates ( $11 \%$ vs. $20 \%$ ).

Villars et al. ${ }^{21}$ examined a multi-component post-discharge intervention (timely follow-up, home visit, telephone call, caregiver hotline) led by a geriatric team in patients with Alzheimer's disease $(n=390)$ and their caregivers. The discharge plan was implemented among patients who had been discharged from a special Alzheimer's acute care unit using telephone contact between geriatric team and the caregiver in the first week after discharge, before the end of the first month and at three and six months. There was no difference in onemonth emergency room re-hospitalization rates $(8.4 \%$ vs. $8.0 \%, p=0.82$ ) when compared with re-hospitalization rates in the year prior to the intervention.

Terayama et al. ${ }^{23}$ evaluated a hospital education program provided to caregivers of outpatients living with dementia $(n=$ 47). The education program involved two 1.5 -h lectures delivered by physicians, nurses, and social workers over two months, with the initial session addressing medication adherence and management of medical complications. The intervention resulted in significant reduction of caregiver burden; mean scores on the Zarit Caregiver Burden decreased from $31.7 \pm 17.6$ (SD) pre-intervention to $27.7 \pm 16.9$ (SD) postintervention ( $p=0.037)$. In addition, caregiver depressive symptoms decreased significantly; mean scores on the Center for Epidemiologic Studies Depression Scale (CES-D) decreased from $14.5 \pm 9.2(\mathrm{SD})$ pre-intervention to $12.1 \pm 7.5$ post-intervention $(p=0.039)$. No significant changes in quality of life of caregivers and patients were reported.

Transitions of Care Interventions. Kable et al. ${ }^{22}$ conducted a mixed methods study which audited medical discharge summaries provided to the primary care physician and caregiver $(n=73)$. The study found that out of the 73 eligible discharges, over $80 \%$ included documentation about medication and significant medication changes, and almost 90\% included documentation about instructions for routine medications. A compliance score of the discharge information provided to patients and caregivers was calculated as the proportion of discharge information that complied with the requirements of the 11 expected criteria outlined in state-based guidelines. The study found no evidence that re-hospitalization decreased as the compliance score increased (OR 0.99, $p=0.33$ ). The study had no information about the readability of the discharge summary provided caregivers.

\section{Quality Appraisal}

Table 2 shows the methodological quality of each of the included studies. One out of the four non-randomized studies were assessed as having high quality. The remaining studies were judged as having unclear quality.

\section{DISCUSSION}

The systematic review highlights that there is limited research on interventions at hospital discharge to guide caregivers in medication management for people living with dementia. Interventions were typically delivered post-discharge by a multidisciplinary team and most targeted administration of medications by caregivers. Of these, two studies reported that discharge interventions had no statistically significant effect on re-hospitalization rates. ${ }^{21,22}$ However, in another study, which employed a multi-component post-discharge intervention, reduction in the proportion of patients hospitalized within 30 days of discharge was reported. ${ }^{24}$ Furthermore, discharge interventions had led to significant reduction in length of stay and caregiver burden.${ }^{23,24}$ No study addressed all aspects of medication management, and outcomes reported in the included studies were heterogeneous.

In this review, two studies tested interventions that extended beyond in-patient care and included multiple components. However, of these, only one reported reduction in 30-day rehospitalization rates ${ }^{24}$. This was the only study to include medication review component that involved simplification of the patient's medical regimen and targeted medication appropriateness. Studies suggest that $19 \%$ of older adults have a medication-related adverse event immediately after hospital discharge, of which $35 \%$ are deemed to be preventable. ${ }^{25}$ Factors contributing to adverse outcomes include complexities in medication management as well as polypharmacy and inappropriate medication use which contribute to caregiver burden. ${ }^{26}$ Comprehensive medication reviews have been shown to successfully reduce inappropriate medication use and improve caregiver understanding in medication management. ${ }^{27,28}$ Pharmacists conducting post-discharge medication review in collaboration with the primary care physician was reported to reduce medication-related problems among older adults. ${ }^{29}$ Therefore, further work should identify opportunities for incorporating post-discharge comprehensive medication reviews in multi-disciplinary interventions that extend beyond in-patient care to facilitate caregiver management of medications in people with dementia at discharge.

Hospital discharge has been reported to be a vulnerable stage in the patient pathway, and communication failures across transitions of care contribute to preventable medication-related problems. ${ }^{25,30-32}$ Two out of the five studies tested discharge interventions that involved communication with the primary care physician. ${ }^{22,24}$ The discharge summary documentation had no effect on outcomes, ${ }^{22}$ while the multidisciplinary team intervention involving collaboration with the primary care 
Table 2 Quality Assessment ${ }^{19}$

\begin{tabular}{|c|c|c|c|c|c|c|c|c|c|c|}
\hline \multirow[t]{2}{*}{ (In alphabetical order): Author, year, reference } & \multicolumn{5}{|c|}{ 3. Quantitative non-randomized } & \multicolumn{5}{|c|}{ 5. Mixed methods } \\
\hline & 3.1 & 3.2 & 3.3 & 3.4 & 3.5 & 5.1 & 5.2 & 5.3 & 5.4 & 5.5 \\
\hline $\begin{array}{l}\text { Boustani et al., 2012 } 24 \\
\text { Kable et al., 201922 }\end{array}$ & No & No & Can't tell & No & Yes & \multirow{4}{*}{ No } & \multirow{4}{*}{ Yes } & \multirow{4}{*}{ No } & \multirow{4}{*}{ No } & \multirow{4}{*}{ Can't tell } \\
\hline Kazui et al., $2004^{20}$ & No & No & Yes & Yes & Yes & & & & & \\
\hline Terayama et al., $2018^{23}$ & No & Yes & Yes & Yes & Yes & & & & & \\
\hline Villars et al., $2013^{21}$ & No & Yes & Yes & No & Yes & & & & & \\
\hline
\end{tabular}

physician to discuss medications showed reduction in the proportion of patients re-hospitalized within 30 days of discharge. ${ }^{24}$ Barriers to effective coordination at transitions of care include incomplete, unclear content and instructions in discharge summaries. ${ }^{33}$ To address the challenge of care transitions for patients and their caregivers, interventions to support effective communication and team-work across transitions of care are important. ${ }^{34-36}$

Most interventions included in this review targeted administration of medications by caregivers. ${ }^{22-24}$ While studies have shown that 50 to $70 \%$ of caregivers assist with medication administration in people living with dementia, caregivers are also engaged in other aspects of medication management. ${ }^{12,37,38}$ These include medication supply, monitoring, and avoiding medication-related harm (making judgement regarding when to decrease or discontinue treatment) as well as communicating with the physician about medications that require review. ${ }^{12,37}$ Caregivers of individuals with dementia have reported that useful interventions to optimize medication management include establishing medication routines, using dose administration aids, and simplifying medication regimens. ${ }^{9}$ However, studies report caregivers of people living with dementia receive limited information at discharge to support them in their medication management roles. ${ }^{32,39}$ The caregiver of an individual with dementia also plays an important role in actively assist with care coordination and communicate with primary care physician. ${ }^{40}$ Therefore, discharge interventions that aim to provide specific guidance to caregivers in all aspects of medication management for people living with dementia and support caregivers in care coordination are needed.

The outcomes measured in the included studies ranged widely. Limited studies assessed clinical outcomes including re-hospitalization $(n=3)$, and most found no significant impact on outcomes assessed. With respect to outcomes reported, quality indicators for medication use were only reported by one study which found lower use of high-risk medications. ${ }^{24}$ Other indicators, such as medication-related harm, difference in inappropriate medications, and adherence, were also not captured. Interestingly, only one study reported caregiver outcomes, the effect of interventions on caregiver burden and strain. ${ }^{23}$ Caregivers are reported to experience significant burden in medication management at transition from the hospital to the home. ${ }^{32,41}$ There is a need for future studies to select appropriate and clinically meaningful measures reporting on medication management measures and patient and caregiver health outcomes.

A comprehensive search strategy was employed across five databases and further searching of reference list, and two authors screened studies by title and abstract, as well as screened full-text studies to determine eligible studies. However, there are several limitations to this review. We only included studies published in English; thus, we may have missed other studies of relevance to international patient populations. This review identified the lack of interventions tested in a clinical trial setting, and most studies reported no effect on patient and caregiver outcomes. Due to heterogeneity of the interventions and outcomes of the included studies, the results were summarized descriptively. Most of the included studies have methodological limitations. In addition, the results of this review were limited to a small number of studies and locations, restricting the generalizability of our findings. Therefore, research is needed to investigate the impact of discharge interventions to guide caregivers in medication management for people living with dementia.

In conclusion, this systematic review illustrates that the evidence on discharge interventions to guide caregivers in medication management for people living with dementia is limited. Multi-disciplinary interventions that extend beyond in-patient care, effective communication to achieve coordination at transitions of care, and specific guidance to caregivers on all aspects of medication management are characteristics that are key to intervention design. Interventions that guide caregivers in all aspects of medication management for people living with dementia and include support for caregivers in care coordination are needed. Measurement of patient and caregiver-centered outcomes, including quality indicators for medication use, are a step forward to expand research in this field.

Supplementary Information The online version contains supplementary material available at https://doi.org/10.1007/s11606-02006442-5.

Acknowledgments: We would like to acknowledge Miss Stefanie Mitreuski for her assistance with systematic search.

Corresponding Author: Mouna J. Sawan, B.Pharm, Hons, PhD; School of Pharmacy School, Faculty of Medicine and Health, The University of Sydney, Camperdown, NSW, Australia (e-mail: mouna. sawan@sydney.edu.au). 
Funding The project and DG is supported by the Australian National Health and Medical Research Council Dementia Leadership Fellowship.

\section{Compliance with Ethical Standards:}

Conflict of Interest: The authors declare that they do not have a conflict of interest.

\section{REFERENCES}

1. Global action plan on the public health response to dementia 2017-2025. Geneva: World Health Organization; 2017. Licence: CC BY-NC-SA 3.0 IGO. Accessed 10/05/2020

2. Cappetta K, Lago L, Phillipson L. Patterns of hospital utilisation in the lead up to a diagnosis of dementia: A longitudinal retrospective study of hospital dementia patients in Australia. Australas J Ageing 2020. doi:https://doi.org/10.1111/ajag. 12770

3. Fox A, MacAndrew M, Ramis MA. Health outcomes of patients with dementia in acute care settings-A systematic review. Int J Older People Nursing. 2020:e12315. https://doi.org/10.1111/opn. 12315

4. Mullan J, Burns P, Mohanan L, Lago L, Jordan M, Potter J Hospitalisation for medication misadventures among older adults with and without dementia: A 5-year retrospective study. Australasian J Ageing 2019;38(4):e135-e41. doi:https://doi.org/10.1111/ajag. 12712

5. Kristensen RU, Norgaard A, Jensen-Dahm C, Gasse C, Wimberley T, Waldemar G. Polypharmacy and Potentially Inappropriate Medication in People with Dementia: A Nationwide Study. J Alzheimers Dis 2018;63(1):383-94. doi:https://doi.org/10.3233/JAD-170905

6. Elliott RA, Goeman D, Beanland C, Koch S. Ability of older people with dementia or cognitive impairment to manage medicine regimens: a narrative review. Curr Clin Pharmacol 2015;10(3):213-21. doi:https:// doi.org/10.2174/1574884710666150812141525

7. Look KA, Stone JA. Medication management activities performed by informal caregivers of older adults. Res Social Admin Pharm 2018;14(5):418-26. doi:https://doi.org/10.1016/j.sapharm.2017.05. 005

8. Lim RH, Sharmeen T. Medicines management issues in dementia and coping strategies used by people living with dementia and family carers: A systematic review. Int J Geriatr Psych 2018;33(12):1562-81. doi:https:// doi.org/10.1002/gps.4985

9. Gillespie R, Mullan J, Harrison L. Managing medications: the role of informal caregivers of older adults and people living with dementia. A review of the literature. J Clin Nurs 2014;23(23-24):3296-308. doi:https://doi.org/10.1111/jocn.12519

10. Allen J, Hutchinson AM, Brown R, Livingston PM. User experience and care for older people transitioning from hospital to home: Patients' and carers' perspectives. Health Expect 2018;21(2):518-27. doi:https://doi. org/10.1111/hex. 12646

11. Gillespie RJ, Harrison L, Mullan J. Medication management concerns of ethnic minority family caregivers of people living with dementia. Dementia (London) 2015;14(1):47-62. doi:https://doi.org/10.1177/ 1471301213488900

12. Noureldin M, Plake KS. Correlates of caregivers' involvement in the management of older adults' medications. Res Social Admin Pharm 2017;13(4):840-8. doi:https://doi.org/10.1016/j.sapharm.2016.09.009

13. Thorpe JM, Thorpe CT, Kennelty KA, Gellad WF, Schulz R. The impact of family caregivers on potentially inappropriate medication use in noninstitutionalized older adults with dementia. Am J Geriatr Pharmacother 2012;10(4):230-41. doi:https://doi.org/10.1016/j. amjopharm.2012.05.001

14. World Health Organization. Transitions of Care: Technical Series on Safer Primary Care Geneva. 2016

15. Moher D, Liberati A, Tetzlaff J, Altman DG. Preferred reporting items for systematic reviews and meta-analyses: the PRISMA statement. BMJ 2009;339. doi:https://doi.org/10.1136/bmj.b2535

16. A spoonful of sugar: medicines management in NHS hospitals. Audit Commission for Local Authorities and the National Health Service in England and Wales, London. 2001. http://www.eprescribingtoolkit.com/ wp-content/uploads/2013/11/nrspoonfulsugar1.pdf. Accessed 01/01/ 2020
17. Hansen LO, Young RS, Hinami K, Leung A, Williams MV. Interventions to reduce 30-day rehospitalization: a systematic review. Ann Intern Med 2011;155(8):520-8. doi:https://doi.org/10.7326/0003-4819-155-8201110180-00008

18. Pluye P, Gagnon M-P, Griffiths F, Johnson-Lafleur J. A scoring system for appraising mixed methods research, and concomitantly appraising qualitative, quantitative and mixed methods primary studies in Mixed Studies Reviews. Int J Nurs Stud 2009;46(4):529-46. doi:https://doi. org/10.1016/j.ijnurstu.2009.01.009

19. Hong QN PP, Fàbregues S, Bartlett G, Boardman F, Cargo M, Dagenais P, Gagnon, M-P GF, Nicolau B, O'Cathain A, Rousseau M-C, Vedel I. Mixed Methods Appraisal Tool (MMAT). Canadian Intellectual Property Office, Industry Canada. 2018. file:///W:/Damien\%20Wennekers/ Included\%20articles/MMAT_2018_criteria-manual_2018-0801_ENG.pdf. Accessed 1/04/2020.

20. Kazui H, Hashimoto M, Nakano Y, Matsumoto K, Yamamura S, Nagaoka $\mathbf{K}$, et al. Effectiveness of a clinical pathway for the diagnosis and treatment of dementia and for the education of families. Int $\mathrm{J}$ Geriatr Psychiatry 2004; 19(9):892-7.

21. Villars H, Dupuy C, Soler P, Gardette V, Soto ME, Gillette S, et al. A follow-up intervention in severely demented patients after discharge from a special Alzheimer acute care unit: impact on early emergency room rehospitalization rate. Int $J$ Geriatr Psychiatry 2013;28(11):1131-40. doi:https://doi.org/10.1002/gps.3932

22. Kable A, Pond D, Hullick C, Chenoweth L, Duggan A, Attia J, et al. An evaluation of discharge documentation for people with dementia discharged home from hospital - A cross-sectional pilot study. Dementia (London, England). 2019;18(5):1764-76. doi:10.1177/ 1471301217728845

23. Terayama H, Sakurai H, Namioka $\mathbf{N}$, Jaime $\mathbf{R}$, Otakeguchi $\mathbf{K}$, Fukasawa R, et al. Caregivers' education decreases depression symptoms and burden in caregivers of patients with dementia. Psychogeriatrics. 2018;18(5):327-33. doi:https://doi.org/10.1111/psyg. 12337

24. Boustani MA, Sachs GA, Alder CA, Munger S, Schubert CC, Guerriero Austrom M, et al. Implementing innovative models of dementia care: The Healthy Aging Brain Center. Aging Ment Health 2011;15(1):13-22. doi:https://doi.org/10.1080/13607863.2010.496445

25. Kanaan AO, Donovan JL, Duchin NP, Field TS, Tjia J, Cutrona SL, et al. Adverse drug events after hospital discharge in older adults: types, severity, and involvement of Beers Criteria Medications. J Am Geriatr Soc 2013;61(11):1894-9. doi:https://doi.org/10.1111/jgs.12504

26. Parsons C. Polypharmacy and inappropriate medication use in patients with dementia: an underresearched problem. Ther Adv Drug Saf 2017;8(1):31-46. doi:https://doi.org/10.1177/2042098616670798

27. Bloomfield HE, Greer N, Linsky AM, Bolduc J, Naidl T, Vardeny $\mathbf{O}$, et al. Deprescribing for Community-Dwelling Older Adults: a Systematic Review and Meta-analysis. J Gen Intern Med 2020. doi:https://doi.org/ 10.1007/s11606-020-06089-2

28. Cross AJ, Etherton-Beer CD, Clifford RM, Potter K, Page AT. Exploring stakeholder roles in medication management for people living with dementia. Res Soc Adm Pharm 2020. doi:https://doi.org/10.1016/j. sapharm.2020.06.006

29. Ahmad A, Nijpels G, Dekker JM, Kostense PJ, Hugtenburg JG. Effect of a Pharmacist Medication Review in Elderly Patients Discharged From the Hospital. Arch Intern Med 2012;172(17):1346-7. doi:https://doi.org/ 10.1001/archinternmed.2012.2816

30. Forster AJ, Clark HD, Menard A, Dupuis N, Chernish R, Chandok N, et al. Adverse events among medical patients after discharge from hospital. Cmaj. 2004;170(3):345-9.

31. Waring $\mathbf{J} \mathbf{M F}$, Bishop $\mathbf{S}$, et al. An ethnographic study of knowledge sharing across the boundaries between care processes, services and organisations: the contributions to 'safe' hospital discharge. Southampton (UK): NIHR Journals Library2014.

32. Chenoweth L, Kable A, Pond D. Research in hospital discharge procedures addresses gaps in care continuity in the community, but leaves gaping holes for people with dementia: a review of the literature. Australasian J Ageing 2015;34(1):9-14. doi:https://doi.org/10.1111/ ajag. 12205

33. Markiewicz O, Lavelle M, Lorencatto F, Judah G, Ashrafian H, Darzi A. Threats to safe transitions from hospital to home: a consensus study in North West London primary care. Br J Gen Pract 2020;70(690):e9-e19. doi:https://doi.org/10.3399/bjgp19X707105

34. Alqenae FA, Steinke D, Keers RN. Prevalence and Nature of Medication Errors and Medication-Related Harm Following Discharge from Hospital 
to Community Settings: A Systematic Review. Drug Saf 2020;43(6):51737. doi:https://doi.org/10.1007/s40264-020-00918-3

35. Garcia-Caballos M, Ramos-Diaz F, Jimenez-Moleon JJ, BuenoCavanillas A. Drug-related problems in older people after hospital discharge and interventions to reduce them. Age Ageing 2010;39(4):430-8. doi:https://doi.org/10.1093/ageing/afq045

36. Snow K, Galaviz K, Turbow S. Patient Outcomes Following Interhospital Care Fragmentation: A Systematic Review. J Gen Intern Med 2020;35(5):1550-8. doi:https://doi.org/10.1007/s11606-019-05366-z

37. Smith F, Francis SA, Gray N, Denham M, Graffy J. A multi-centre survey among informal carers who manage medication for older care recipients: problems experienced and development of services. Health Soc Care Commun 2003;11(2):138-45.

38. Schmidt NE, Steffen A, Meuser TM. Impairment for Medication Management in Older Adults: Validity of a Family Report Measure. Clin Gerontol 2020;43(3):350-62. doi:https://doi.org/10.1080/07317115. 2019.1703064
39. Manias E, Bucknall T, Hughes C, Jorm C, Woodward-Kron R. Family involvement in managing medications of older patients across transitions of care: a systematic review. BMC Geriatr 2019;19(1):95. doi:https://doi. org/10.1186/s12877-019-1102-6

40. Coleman EA, Smith JD, Frank JC, Min SJ, Parry C, Kramer AM Preparing patients and caregivers to participate in care delivered across settings: the Care Transitions Intervention. J Am Geriatr Soc 2004;52(11):1817-25. doi:https://doi.org/10.1111/j.1532-5415.2004. 52504.x

41. Beardon S, Patel K, Davies B, Ward $\mathbf{H}$. Informal carers' perspectives on the delivery of acute hospital care for patients with dementia: a systematic review. BMC Geriatr 2018;18(1):23. doi:https://doi.org/10. 1186/s12877-018-0710-x

Publisher's Note: Springer Nature remains neutral with regard to jurisdictional claims in published maps and institutional affiliations. 